\title{
EDUCAÇÃO EM VALORES: UM POSSÍVEL CAMINHO PARA A SUPERAÇÃO DA RAZÃO INSTRUMENTAL RUMO À FORMAÇÃO DO CIDADÃO
}

\author{
Natalia Branco Lopes KRAWCZUN ${ }^{1}$
}

RESUMO: O trabalho tem como objetivo propor uma reflexão a respeito da introdução de valores na ação educativa institucional, cujo objetivo volta-se à implementação de um espaço profícuo ao desenvolvimento do cidadão. Para isso, a partir das obras da filósofa espanhola Adela Cortina e do filósofo alemão Jürgen Habermas busca-se estabelecer um raciocínio a respeito da inevitável inserção de valores na ação, destinada a provocar os educandos à incorporação de uma postura participativa, que é essencial para elevá-los à condição de cidadão. Para isso, parte-se inicialmente da análise das diferentes formas de estabelecimento das relações interpessoais. A partir das considerações de Cortina acerca dos estudos de Jonathan Sacks e Thomas Hobbes, realiza-se um cotejo entre aliança e contrato, demonstrando que embora os direitos e deveres do cidadão estejam estabelecidos por meio de um contrato, os seus fundamentos e a garantia de seu funcionamento consubstanciam-se na aliança. Outro aspecto abordado, refere-se à superação da ação instrumental, considerada por Cortina como nefasta à formação do sujeito autônomo. Destaca-se a contribuição da educação escolar, em todos os seus níveis, no tocante ao desenvolvimento de uma sociedade democrática que conta com a participação ativa de seus sujeitos pertencentes e conscientes de suas alianças. Aponta-se que para que esse projeto aproxime-se da realidade é fundamental que os educadores, bem como os demais agentes vinculados às instituições educacionais, articulem em sua práxis os valores mínimos destacados por Adela Cortina, quais sejam: liberdade, igualdade, respeito ativo, solidariedade e o diálogo.

PALAVRAS-CHAVE: Cidadania. Educação. Valores.

\section{Introdução}

Compreender o ser humano a partir de suas relações interpessoais não é uma tarefa simples, porém, necessária, sobretudo para o campo da educação. Diante da complexidade do desafio, considero como um bom ponto de partida a discussão realizada pela filósofa espanhola Cortina (2008) que em sua obra "Aliança e contrato" apresenta um interessante cotejo entre a cultura judaico-cristã e o Estado contratualista, trazendo à tona duas perspectivas diferentes de analisar os laços que unem os seres humanos. O primeiro baseia-se na ideia do homem como "animal político" e a segunda como "animal social".

Para melhor diferenciar as respectivas categorias, a autora explica que como animal político o homem "[...] cria instituições próprias da sociedade política, os Estados, os governos, os sistemas políticos. Como animal social, cria as instituições próprias da sociedade

\footnotetext{
${ }^{1}$ Professora UNINORTE - Faculdade Norte Paranaense. Mestre em Educação. UEL - Universidade Estadual de Londrina. Londrina - PR - Brasil. 86057-970 - nataliabrancoprof@ hotmail.com.
} 
civil", como por exemplo, as unidades familiares, comunidades e as tradições morais (CORTINA, 2008, p.13).

Esses dois modos distintos de viver coletivamente são reveladores de duas histórias que aqui serão abordadas. A primeira delas evidenciada neste trabalho, toma por base as considerações de Cortina (2008) acerca da obra "Leviatã" de Thomas Hobbes, no qual se confere ao contrato a função de sustentáculo da vida compartilhada.

Hobbes (2008) compreende, ao contrário de Aristóteles, que o homem não é por natureza um "animal político". Todavia, acredita que o surgimento, bem como a manutenção da "comunidade política", é viável por meio de um instrumento artificial: o contrato (CORTINA, 2008).

Pessimista quanto à natureza humana, Hobbes (2008) parte do princípio de que o homem é naturalmente egoísta. Assim sendo, o desejo de preservar seus próprios interesses em detrimento dos outros poderá ser contido tão somente por meio de um acordo (CORTINA, 2008).

Sob essa ótica, Hobbes (2008) esclarece que tão somente o Estado, na condição de detentor do poder civil, poderia exercer controle sobre os impulsos naturalmente agressivos da humanidade. Desse modo, sujeitando-se o homem a um contrato, a uma lei, o Estado passaria a ser o garantidor de que a vida e os bens do indivíduo não seriam vilipendiados por outrem (HOBBES, 2008). Assim, um acordo é selado e estruturado sob o interesse e o "medo recíproco" (CORTINA, 2008).

É interessante mencionar que em relação ao vínculo pautado na percepção hobbesiana, Cortina (2008) considera que no momento em que o contrato, um instrumento inerente ao direito privado, passa a reger a vida política, ele a organiza "sob a forma de um contrato".

De fato, não é difícil identificar que a lógica do contratualismo alastrou-se na sociedade civil e, com uma perceptível força, o discurso dos direitos e deveres tem regido as relações sociais dentro das comunidades.

É certo que as associações civis necessitam observar a legislação. Em momento algum, a importância da lei é desconsiderada. Cortina (2008) aponta o seu caráter de imprescindibilidade, sobretudo para evitar arbitrariedades, violação de direitos e humilhações. Porém, a propagação dessa mentalidade no âmbito da sociedade civil é uma questão angustiante, mesmo porque o direito não se tem mostrado "autosuficiente" para acalmar os ânimos de homens ávidos pela satisfação de seus próprios desejos. Mesmo porque é importante lembrar que nem todas as ações que um indivíduo pode desferir em detrimento à outrem é objeto de coerção jurídica. 
Diante disso, Cortina (2008, p.25) ressalta que “[...] o discurso do contrato e dos direitos precisa pressupor o relato da aliança e da obrigação nascida do reconhecimento recíproco", ou seja, em Hobbes (2008) é possível identificar a existência de um vínculo que encontra no contrato o meio mais viável de realizar pactos e estabelecer elos entre os indivíduos. Todavia, a partir da perspectiva de Sacks (2005), Cortina (2008) apresenta a possibilidade de um diferente fundamento para as relações interpessoais que são estabelecidas por meio da "aliança".

A aliança fundamenta o segundo modo de viver que se pretende confrontar cuidadosamente com a cultura contratualista. A cautela se deve ao fato de que, embora elementos antagônicos sejam evidenciados, existe um surpreendente espaço de complementaridade que se desvela por meio da atuação de diferentes instituições. A ideia central é a de que o homem apenas passa a ser "reconhecido como pessoa" a partir do outro. Semelhante compreensão pode ser identificada em Buber (1974) quando afirma que o encontro em que há totalidade do homem, ocorre na reciprocidade, na relação entre "eu e tu", ou seja, “[...] a natureza do homem não é contida somente na comunidade, na unidade com o homem, mas numa unidade que repousa exclusivamente sobre a realidade da diferença entre eu e tu". (BUBER, 1975, p.25)

À medida que as diferenças entre o contrato e a aliança são salientadas, mais se expõe a fragilidade do primeiro, visto que a manutenção de um contrato é sustentada pelas partes envolvidas, ao passo que "[...] quem reconhece o outro como sua parte e tem consciência de estar unido a ele por uma aliança não rompe o vínculo nos tempos difíceis [...]”. (CORTINA, 2008, p.19).

Diante disso, é necessário ponderar acerca da responsabilidade cabível a cada indivíduo enquanto integrante de uma comunidade em relação a temas como, conforme exemplifica Sacks (2005), “[...] aborto, eutanásia, desintegração da família, sistema de justiça criminal, consumismo" e por que não a educação?

Sacks (2005), a partir dos valores arraigados na cultura hebraica, traz uma perspectiva de responsabilidade coletiva em que cada um dos sujeitos se torna corresponsável pelos caminhos seguidos por sua nação. Assim, delegar tão somente ao Estado a responsabilidade pela educação, erradicação da fome, auxílio às vítimas de catástrofes naturais, por exemplo, demonstra a ocorrência da substituição da ética pela política. Em outras palavras, pode-se dizer que ter um estado não basta, é necessário ter uma sociedade composta por cidadãos e: 
Ser cidadão de um país ou morador de um bairro significa, de uma forma ou de outra, estar envolvido em algum tipo de destino coletivo. Se meus vizinhos deixam suas casas se deteriorarem, minha casa passa a valer menos. Se compatriotas permitem a quebra de padrões morais, toda a população sofre conseqüências. Aquilo que me acontece é apenas em parte determinado pelo que faço. È determinado também pelo que os outros fazem. Queiramos ou não, somos afetados por aqueles que vivem a nossa volta. (SACKS, 2005, p.116).

A sociedade é composta por indivíduos que integram um grupo e são afetados pelas ações dos demais, pois “[...] fazemos parte de uma família, uma comunidade e sociedade, e compartilhamos sua inocência ou culpa" (SACKS, 2005, p.182).

Ao comparar a aliança e o contrato, a partir da análise de duas diferentes tradições, é possível perceber distintas formas de viver, de estabelecer compromissos, de relacionar com o outro e que certamente influencia na formação do indivíduo.

\section{A educação cidadã}

A junção entre aliança e contrato é elemento fundamental para que a cidadania seja contemplada em sua totalidade. Logo, a educação que se volta para a formação do cidadão não poderia deixar de considerar o caráter de imprescindibilidade de ambos os elementos.

Então, para que seja possível que a escola "eduque na cidadania" ${ }^{2}$, Cortina (2005) indica a importância da articulação de valores junto à atuação do docente, pois:

[...] aprendemos a ser cidadãos, assim como aprendemos quase tudo, e o fazemos não por força da lei e do castigo, e sim por gosto. Ajudar a cultivar as faculdades (intelectuais e sencientes) necessárias para apreciar os valores cidadãos é educar na cidadania local e universal. (CORTINA, 2005, p.173).

\footnotetext{
${ }^{2}$ É importante frisar que a educação não ocorre tão somente dentro da escola, ou da igreja ou no âmbito familiar: o seu alcance é o mais extensivo e menos restritivo possível, seja ela formal ou não. Não há uma única forma, um único modelo, nem mesmo um único conceito, e a escola não é o único local em que ela ocorre, nem é o professor o seu guardião, ainda que a prática escolar educativa, como um processo formal e intencional tenha profunda relevância na formação humana. Nesse sentido, Brandão (1991, p.7) salienta: “[...] ninguém escapa da educação. Em casa, na rua, na igreja, de um modo ou de muitos, todos nós envolvemos pedaços da vida com ela: para aprender, para ensinar, para aprender-e-ensinar. Para saber, para ser ou para conviver, todos os dias misturamos a vida com a educação. [...] Não há uma forma única nem um único modelo de educação; a escola não é o único lugar em que ela acontece e talvez nem seja o melhor; o ensino escolar não é a única prática, e o professor profissional não e seu único praticante".
} 
Nessa direção, a professora Rios (2008) tece algumas considerações valiosas quanto à importância da incorporação dos valores morais no trabalho docente. De acordo com a autora, a escola é um local e um tempo estruturados para que seja possível, com base em projetos, conciliar o conteúdo com a formação da cidadania e, para isso concretizar-se é necessário considerar que a aula possui dimensões éticas que são articuladas com as demais dimensões da ação pedagógica.

A dimensão ética do trabalho do professor articula-se em três dimensões: a técnica, a estética e a política. A técnica refere-se ao domínio que o docente possui quanto aos "conteúdos e técnicas" necessários para atuar em sua área. A estética relaciona-se com a "sensibilidade na relação pedagógica e sua orientação numa perspectiva criadora". Já, a política remete-se à “[...] participação na construção coletiva da sociedade e ao exercício de direitos e deveres". (RIOS, 2008, p.82).

Dessa forma, o trabalho pedagógico assume responsabilidades que sem a sua articulação com a moral, seria impossível sustentá-las. De fato, o compromisso com a dimensão ético-política da educação firma-se pelo exercício do poder democrático em todas as instituições, inclusive na escola, pois a liberdade, a autonomia, condições para a cidadania, são cultivadas no cotidiano das relações na qual o diálogo e o reconhecimento do outro tornam-se ações fundamentais, pois "o gesto do professor ensina". (RIOS, 2008).

Nesse sentido, Cortina (2005) chama a atenção para a existência de "valores morais próprios do cidadão", sem os quais seria impossível pensar numa educação cívica capaz de transcender o âmbito do contrato e estender-se à aliança. Dentre eles Cortina (2008) elenca a liberdade, a igualdade, o respeito ativo, a solidariedade e o diálogo como valores mínimos e essenciais a todos os seres humanos indistintamente.

\section{Educação e valores}

Um dos clássicos problemas relacionados à educação moral, de acordo com Cortina (1993, p.210) girava em torno da seguinte questão: "É possível ensinar a virtude"? Quanto ao assunto, a autora salienta que, embora ainda não se tenha uma resposta satisfatória, o problema sofreu uma curiosa mutação. Atualmente, a pergunta deslocou-se para: "Vale a pena ensinar a virtude"?

A filósofa atribui essa alteração à prevalência de uma razão instrumental que impulsiona a educação a ater-se apenas ao campo técnico como meio mais eficaz de vencer na 
vida. O potencial tecnológico é visto como um mecanismo que "[...] parece aumentar as possibilidades sociais de liberdade e bem-estar". (CORTINA, 1993, p.211).

De fato, as previsões de Adorno e Horkheimer (1985) acerca da prevalência da razão instrumental parecem cada vez mais condizentes com a realidade contemporânea. Os autores mencionados compreendem que a técnica, quando passa a ser a essência do esclarecimento, reconhece apenas aquilo que desvela (ADORNO; HORKHEIMER, 1985). Com o objetivo de transformar o desconhecido e dominar a natureza a seu favor, a razão instrumental converte o mito em esclarecimento e reduz a natureza à "mera objetividade". Todavia os autores advertem: “[...] o preço que os homens pagam pelo aumento de seu poder é a alienação daquilo sobre o que exercem o poder. O esclarecimento comporta-se com as coisas como o ditador se comporta com os homens. Este conhece-o na medida em que pode manipulá-los". (ADORNO; HORKHEIMER, 1985, p.24).

Dessa forma, busca-se incessantemente vasculhar todos os mistérios, rechaçar o ilusório para "melhor prover e melhor auxiliar a vida" (ADORNO; HORKHEIMER, 1985, p.20).

Essa nefasta racionalidade que também penetrou nas escolas constitui, não o único, mas um significativo obstáculo à formação de cidadãos autônomos e solidários, visto que “[...] é impossível construir uma sociedade autenticamente democrática contando unicamente com indivíduos técnicos e socialmente destros”, é necessário ir adiante. (CORTINA, 1993, p.213).

Para isso, Cortina (2005) aponta além da autonomia e solidariedade, um rol de valores fundamentais necessários para a manutenção da democracia e exercício da cidadania que conta necessariamente com uma educação em valores e não meramente instrumental.

Neste momento, é importante esclarecer que o entendimento relativo à educação em valores incorporada por esse trabalho não se assemelha com a ideia de instruir os educandos quanto aos procedimentos e atitudes supostamente adequadas a serem seguidas. Não se trata de transmissão de valores com base em ideais prédefinidos, mas sim da possibilidade de inserir no ambiente escolar um procedimento dialógico capaz de levar os alunos a agir conforme e refletir acerca de seu papel de cidadão.

A transmissão de virtudes, nos moldes de uma cartilha prédefinida como instrumento de domesticação, não atende a uma dimensão de cidadania cosmopolita, na qual o respeito à pluralidade é fundamental. Assim, educar em valores, no atual contexto, implica necessariamente em "[...] abandonar a versão tradicional do caráter instrumental, centralizada 
na transmissão de comportamentos virtuosos com base em ideais préestabelecidos". (GOERGEN, 2001, p.148). Desse modo, compartilha-se do seguinte entendimento:

O correto agir é o resultado de um projeto de aprendizagem, uma tarefa educativa. $\mathrm{O}$ correto agir não preexiste na forma de prescrições que a educação teria como que em carteira para transferir aos alunos. A educação, portanto, não pode gerar nos alunos um conjunto acabado de disposições (virtudes) voltadas para a justiça, para o respeito ou a solidariedade. Em outros termos, não é pela educação que alguém se torna justo. $\mathrm{O}$ que a educação pode fazer é abrir aos alunos o mundo do agir moral por meio de um processo pedagógico/reflexivo/comunicativo a respeito das proposições morais que integram o ambiente cultural. (GOERGEN, 2001, p.152-153).

De fato, o desenvolvimento de uma consciência moral não corresponde a uma automática internalização de normas, mas compreende um "processo de degustação", no qual aspectos emocionais, cognitivos e éticos relacionam-se concomitantemente (CORTINA, 2005).

No entanto, rechaçar uma conceituação estática do agir moral não significa aderir ao relativismo; na verdade, trata-se de compreender que existem valores mínimos que conferem aos homens a condição de seres humanos e precisam ser incorporados pela educação. Assim, salienta-se:

O relativismo, então, carece de base, porque fomos aprendendo ao longo dos séculos que qualquer ser humano, para sê-lo plenamente, deveria ser livre e aspirar à igualdade entre os homens, deveria ser justo, solidário e respeitar ativamente sua própria pessoa e as outras pessoas, trabalhar pela paz e desenvolvimento dos povos, conservar o meio ambiente e entregá-lo às gerações futuras não pior do que o recebeu, tornar-se responsável por aqueles que entregaram a seus cuidados e estar disposto a resolver por meio do diálogo os problemas que podem surgir com aqueles que compartilham com ele o mundo e a vida. (CORTINA, 2005, p.180).

Os "valores cívicos", assim definidos por Cortina (2005) são os elementos que integram os mínimos considerados por todos como irrenunciáveis, mesmo em meio à diversidade. Ou seja, em meio aos diversos "códigos morais" que transitam nos âmbitos familiares, religiosos e profissionais, a ética cívica faz parte de diferentes grupos pertencentes a todos esses setores da vida e a muitos outros.

Certamente, o objetivo da educação em valores consiste em indicar os caminhos que devem ser trilhados, "mas em explicitar os mínimos morais que uma sociedade democrática deve transmitir" (CORTINA, 2009), valores esses irrenunciáveis que “[...] os membros de 
uma sociedade pluralista compartilham, sejam quais forem suas concepções de vida boa, seus projetos de vida feliz". (CORTINA, 2005, p.149).

Nessa perspectiva, os valores cívicos constituem um vínculo capaz de unir membros pertencentes aos mais variados núcleos sociais; seja como membros de uma determinada família, profissão, religião ou vizinhança. Por esse motivo, a ética cívica é considerada pluralista e própria dos membros de uma comunidade civil e não do Estado. Isso significa afirmar que, apesar de ser essa ética pública, própria do cidadão, que "legitima as instituições políticas", ao Estado cumpre o papel de respeitá-la e observá-la (CORTINA, 2008). De mais a mais, a ética cívica brota da realidade social, como um conjunto de valores e princípios compartilhados em meio ao pluralismo.

A superação da ação instrumental como um possível passo para a construção de uma práxis comunicativa

Habermas, assim como os demais integrantes da Teoria Crítica da Escola de Frankfurt, herdou não apenas a preocupação de identificar os problemas da sociedade contemporânea, mas também de buscar saídas capazes de torná-la melhor.

Ao perceber a filosofia, desde a época do iluminismo, reduzida à "subsistemas particulares e à racionalidade instrumental", cujo esvaziamento da razão foi desvelado por meio da desumanização do homem e da capacidade de manipular, de forma instrumental, as relações sociais, os frankfurtianos posicionaram-se contra a razão iluminista. Além de criticar o modelo técnico-cientifico então vigente, bem como a instrumentalização das relações sociais, propuseram, por meio da teoria crítica, um novo conceito de racionalidade (PIZZI, 1994).

É certo que o iluminismo inicialmente ofereceu à humanidade a falsa sensação de que a razão estaria ao seu serviço. Contudo, com o passar do tempo, a promessa do progresso e da contínua evolução revelou sua fragilidade perante às crescentes denúncias reveladoras da manipulação tanto biológica como ideológica dos homens pela ciência (MÜHL, 2003).

Dessa fonte, economistas também se saciaram. Ao empresário, por exemplo, a racionalidade instrumental demonstrou-se conveniente para sustentação de um sistema que se pauta pela "[...] racionalidade do lucro e da expropriação da mais valia" (FREITAG, 1986, p.91). A grande questão é que numa sociedade imersa no sistema capitalista, como ocorre no Brasil, a vantagem financeira passa a ser o seu maior objetivo e o "sucesso a qualquer custo" torna-se elemento aceito acriticamente". Assim, instrumentalizar o ser humano passa a ser a essência de um ethos imprescindível para estruturar um sistema que se alimenta de desníveis sociais (OLIVEIRA, 1993). 
No âmbito da administração estatal, Weber (2004) considerou a absorção da razão instrumental como aparato de execução de ordens e efetividade de mecanismos de controle dos indivíduos sujeitos aos seus mandos (FREITAG, 1986).

Diante desse quadro, a ciência moderna revelou-se envolta num emaranhado de contradições. Ou seja, se por um lado, o convite a um futuro promissor é permanentemente feito aos sujeitos, por outro, a oportunidade de manipulá-los e subjugá-los não é descartada. Esse paradoxo pode ser observado no seguinte movimento: ao mesmo tempo em que os indivíduos recebem um convite para pensar e sentir de forma autônoma, o moderno conhecimento científico extirpa qualquer fundamento subjetivo de pensamento, impondo aos sujeitos a validade de um conhecimento externo e estranho (MÜHL, 2003).

Consequentemente, as críticas dirigidas à racionalidade moderna respingam na educação, pois é necessário lembrar-se que diante do ideal pedagógico do iluminismo de "formar um sujeito crítico e transformador, disseminar a racionalidade como fonte de todo o conhecimento como compreensão universal", a educação assumiu um papel "[...] emancipador da humanidade, lançando-se à responsabilidade de ser o principal recurso para a construção de uma sociedade livre, justa e igualitária". (MÜHL, 2003, p.33).

Todavia, diante do reducionismo, bem como do caráter instrumental da razão, constatou-se, com o decorrer do tempo, que a educação não desempenhou o promissor papel emancipatório, mas revelou-se paradoxalmente como "instrumento de implementação de uma nova barbárie", sujeitando os indivíduos e condicionando-os aos interesses econômicos e ideológicos predominantes.

Desse modo, a razão perdeu sua característica emancipatória e, como consequência desse movimento, também a educação a perdeu. É inegável que dentro desse contexto devastador, pensar em formação da cidadania em qualquer âmbito e, mais especificamente na escola, soa um tanto utópico. Especialmente quando se identifica um caráter de incompatibilidade entre valores essenciais de cidadania e uma racionalidade que se alastrou e fundamentou-se sob a égide do "ethos do sucesso a qualquer preço" 3 .

Em linhas gerais, a constatação de que essa racionalidade apresenta-se incompatível no que tange à formação do cidadão enquanto ser livre, autônomo, reflexivo e solidário, é um exercício lógico. Todavia, é sobremodo importante assinalar que, apesar da razão vigente apresentar-se inviável para a consecução desse fim, uma nova via há de ser eleita para que a educação honre com seu compromisso ético, político e jurídico de formar o cidadão.

${ }^{3}$ Expressão utilizada por Boff (2004). 
Em virtude disso, destaca-se a necessidade da educação voltar a sua atenção para um novo paradigma de racionalidade que parece ser viável no que tange à construção de uma nova ética, a partir de uma nova razão comunicativa. Em outras palavras, existem elementos relevantes que são inerentes à racionalidade comunicativa e que vale a pena serem colocados à prova pela educação que de fato deseja formar o cidadão ${ }^{4}$.

Tais elementos serão destacados no decorrer do trabalho; entretanto, o seu caráter de contraposição a uma razão que inviabiliza o projeto de cidadania será destacado no presente tópico a partir das considerações ressaltadas pelo filósofo alemão, integrante da escola de Frankfurt, Jürgen Habermas.

Com efeito, ao propor a união do saber teórico com a atividade humana, Habermas (2001) rechaçou a racionalidade que submete a verdade aos interesses da ciência empíricoanalítica. Assim como as demais éticas do diálogo, o filósofo faz um interessante convite à razão que refuta as arbitrariedades subjetivistas tendentes a manter a prevalência de interesses individuais em detrimento dos universais (CORTINA, 2009).

Habermas (2001) compreende, assim como Adorno e Horkheimer (1985), que o agir instrumental é orientado pelo saber analítico. Sendo assim, suas estratégias passam a não ser muito confiáveis, uma vez que se guiam por deduções que podem ser tanto verdadeiras como falsas. Contrapondo-se a essa racionalidade, Habermas (2001) propõe a ação comunicativa na qual a validade das estratégias e das regras técnicas pautam-se pela "validade de enunciados empiricamente verdadeiros", sendo a validade das normas sociais assegurada pelo reconhecimento intersubjetivo valorativo e, portanto, consensual.

Para melhor exemplificar como as razões em destaque diferenciam-se, o filósofo alemão demonstra que as ações humanas na sociedade são definidas por uma racionalidade que pode ser orientada tanto em direção ao êxito quanto para o entendimento, conforme o quadro abaixo:

\begin{tabular}{|c|l|l|}
\hline $\begin{array}{l}\text { Orientação da ação } \\
\text { Situação da ação }\end{array}$ & Ação orientada ao êxito & $\begin{array}{l}\text { Ação orientada ao } \\
\text { entendimento }\end{array}$ \\
\hline Não-social & Ação instrumental & \\
\hline Social & Ação estratégica & Ação Comunicativa \\
\hline
\end{tabular}

${ }^{4}$ É importante esclarecer que este trabalho não sugere que a utilização da via comunicativa é por si só suficientemente capaz de formar o cidadão. Não há garantias, mesmo porque a formação humana não se atrela tão somente à educação e, muito menos à educação meramente institucional. 
Fonte: Habermas (2003b, p.366).

De acordo com Habermas (2003b), quando orientado ao êxito, o ator adota uma espécie de ação que pode ser definida como "ação racional meio-fim", visto que o sujeito deseja é atuar eficazmente para atingir o seu objetivo. Essa ação pode ser tanto instrumental, quanto estratégica.

O filósofo esclarece que em sede de ação instrumental, o sujeito intervém em um mundo objetivo de "estados de coisas", o que, portanto, não implica o estabelecimento de uma relação entre sujeitos. Entretanto, em se tratando de ações estratégicas, o agir direcionado ao êxito constitui uma espécie de ação social marcada pelo alto grau de influência que um sujeito possui em relação às decisões de seu oponente racional.

O termo "oponente" parece adequar-se à posição que os sujeitos ocupam nessa relação, pois no agir estratégico alcançar o êxito é a meta, e, para isso, o ator vale-se de mecanismos de indução para fazer com que o outro aceite o seu ponto de vista. Nos casos mais extremos, mentiras e ameaças também são utilizadas como meio de garantia do sucesso. Indubitavelmente, na "ação racional meio-fim", não há vínculo de reciprocidade, mas sim a prevalência de um sobre o outro (o seu oponente). Nesse contexto, não há espaço algum para o estabelecimento de uma relação baseada nos valores mínimos da ética cívica descritos no capítulo anterior.

Limitando-se a análise em questão ao campo social, pode-se afirmar que, na ação comunicativa, os atores envolvidos não se coordenam por meio de um "cálculo egocêntrico", cujo objetivo volta-se para a obtenção dos resultados desejados, uma vez que se busca estabelecer um acordo mediante o entendimento (HABERMAS, 2003b).

Dessa forma, o agir comunicativo enreda-se no consenso entre as partes, no qual o acordo não será imposto mediante violência, nem terá sido fruto de mera coincidência, mas sim de uma ação ético-comunicativa mediada pela razão, na qual o uso da linguagem volta-se para o entendimento, ou seja:

Ao definir a ação estratégica e a ação comunicativa como dois tipos de ações distintas, parto do pressuposto de que as ações concretas podem ser classificadas segundo esses dois pontos de vista. Quando falo em estratégico e comunicativo, não apenas pretendo nomear dois aspectos analíticos em que a mesma ação possa ser descrita como um processo de influência recíproca por parte dos oponentes que atuam estrategicamente, de um lado e como processo de entendimento entre membros e de outro como um processo de entendimento entre membros de um mesmo mundo da vida. Mas são as ações sociais concretas que podem ser distinguidas de acordo com o que os participantes adotem, ou uma atitude orientada para o sucesso, ou uma 
atitude orientada para a compreensão. (HABERMAS, 2003b, p.367, tradução nossa).

O filósofo deixa claro que as ações em questão são antagônicas. O que vale dizer que, adotar uma delas acarretará a exclusão da outra.

Habermas (2003a), em sua obra "Consciência Moral e Agir Comunicativo", atenta também para o fato de que as diferentes formas de utilização da linguagem implicam a adoção de posturas específicas. Nesse caso, ele explica que toda expressão que possui sentido, seja ela verbal ou não, pode ser identificada a partir de duas perspectivas: na primeira como "ocorrência observável" e, na segunda como "objetivação inteligível de um significado" (HABERMAS, 2003a, p.39).

Na primeira hipótese um determinado proferimento ocorre simplesmente sem qualquer preocupação com o seu significado e, nesse caso, a postura adotada é denominada por Habermas (2003a) como "objetivante". Todavia, se a linguagem for utilizada com o fim de proporcionar o mútuo entendimento, a postura é definida como "performativa". "Ou a gente diz o que é o caso ou o que não é o caso ou bem a gente diz algo para outrem, de tal modo que ele compreenda o que é dito. Só o segundo modo do uso lingüístico está interna ou conceitualmente ligado às condições de comunicação". (HABERMAS, 2003a, p.40).

Ou seja, quando a palavra é simplesmente enunciativa não há comunicação, posto que a linguagem não visou o consenso sobre algo que se tem em mente. Já, na segunda forma do uso da linguagem, ao contrário da primeira, a compreensão de quem ouviu é fundamental para o estabelecimento de um agir comunicativo, cuja postura adotada é performativa (HABERMAS, 2003a). Ao assumir a atitude performativa os intérpretes, necessariamente, envolvem-se nas negociações relativas à validez daquilo que é proferido. Dessa maneira, o autor destaca:

A atitude performativa permite uma orientação mutua por pretensões de validade (verdade, correção normativa, sinceridade) que o falante ergue na expectativa de uma tomada de posição por sim/não da parte do ouvinte. Essas pretensões desafiam uma avaliação crítica, a fim de que o conhecimento intersubjetivo de cada pretensão particular possa servir de fundamento a um consenso racionalmente motivado. Ao se entenderem mutuamente na ação performativa, o falante e o ouvinte estão envolvidos, ao mesmo tempo, naquelas funções que as ações comunicativas realizam para a reprodução do mundo em comum. (HABERMAS, 2003a, p.42). 
Assim, pode-se dizer que a ação, quando orientada para a compreensão, despoja-se da postura objetivante e assume uma atitude performativa, na qual os sujeitos envolvidos agem comunicativamente em busca de mútua compreensão.

A prática comunicacional, dessa forma, afasta-se de um sentido cognitivo-instrumental e fundamenta-se em critérios orientadores quanto às exigências de validades necessárias ao reconhecimento intersubjetivo (HABERMAS, 1990), no qual os valores de igualdade, respeito ativo, solidariedade e liberdade são inevitavelmente postos em prática.

Ao articular-se a racionalidade comunicativa à educação escolar é possível constatar que o diálogo oferece um potencial de conscientização não resultante de uma razão monológica, instituída sob os moldes de uma postura objetivante, ou ainda persuasiva ou até mesmo violenta, conforme prescreve a ação voltada ao êxito (HERMANN, 1999).

Sob essa perspectiva, quando Cortina (2008) afirma que os valores morais não são subjetivos, mas sim intersubjetivos, a autora critica a educação como "técnica de esclarecimento de valores", justamente por constituir um instrumento de doutrinação.

Numa democracia autêntica, afirma a autora, é necessário promover a educação voltada para o fomento de valores como a autonomia e solidariedade. Esse compromisso, no entanto, não é contemplado pela racionalidade instrumental que visa tão somente à formação de indivíduos "tecnicamente destros", aptos a atingir o bem-estar e não a "autorrealização" (CORTINA, 1993).

Ao distinguir bem-estar de autorrealização, Cortina (1993) esclarece que o primeiro conceito entrelaça-se com a obtenção de destreza técnica, enquanto que o segundo, necessariamente, com uma educação em valores. Adquirir habilidades técnicas significa conhecer e dominar os conhecimentos instrumentais que auxiliam os indivíduos a “defenderem-se na vida". Outro ramo dessa espécie de habilidade, que é denominada como "social", empenha-se em ensinar aos alunos a "capacidade de criar ao seu redor uma boa trama de relações com pessoas bem situadas" que poderiam prestar auxílio e assim contribuir para o êxito profissional (CORTINA; NAVARRO, 2001, tradução nossa).

Considerando essa definição, a autora questiona se as habilidades técnicas e sociais são suficientemente capazes de fazer com que os indivíduos não somente "se defendam na vida", mas que também "triunfem" nela. Em resumo, ao considerar os valores que fundamentam uma sociedade que se diz democrática, torna-se dificultoso concluir que tão somente a aquisição de destrezas técnicas contribui para a construção de uma sociedade democrática. Assim, a filósofa acrescenta que "[...] tal sociedade há de sustentar-se em valores nos quais a razão instrumental é cega, valores como a autonomia e solidariedade que 
compõem inevitavelmente a consciência racional das instituições democráticas", inclusive a escola (CORTINA; NAVARRO, 2001, p.178, tradução nossa).

Diante dessas considerações, vale frisar que Cortina (1993) em momento algum desconsidera os avanços técnicos, mas chama a atenção para o caráter de imprescindibilidade que os valores possuem, pois são eles que irão orientar o agir do homem para a "liberdade ou opressão" (CORTINA, 2005) e, em meio à opressão, o homem não age em condições propícias para o cultivo da cidadania. Nesse aspecto, a autora aproxima-se muito da interpretação habermasiana no tocante à insuficiência da racionalidade instrumental sustentar uma sociedade, cuja postura autônoma e livre é desejável aos cidadãos que dela fazem parte.

Refletir sobre uma possível contribuição da ação comunicativa no âmbito escolar é um convite difícil de recusar, pois, na educação contemporânea e, mais especificamente no Brasil, “[...] transformar a prática pedagógica, buscando além da aprendizagem um desenvolvimento integral do ser humano" é uma questão que tem sido constantemente levantada pela literatura (MAIA; BANDEIRA, [19--], p.6).

De acordo com o acatado, vale reforçar que, em relação ao "compromisso integral" acima mencionado, não se pode perder de vista que, além do compromisso pedagógico, existe um compromisso ético-político que compreende a formação do cidadão que é tão importante quanto o primeiro.

A ação comunicativa tem sido reincidentemente suscitada como uma nova alternativa orientadora da relação entre o aluno e o professor no contexto escolar. Como se observa, em Habermas é possível contemplar o liame que o diálogo estabelece entre os indivíduos, no qual os sujeitos interagem com comprometimento. $\mathrm{Na}$ ação comunicativa, é possível identificar o consenso como fruto de uma decisão coletiva e não como imposição coercitiva. Para isso, todos possuem a oportunidade de participação igualitária, exatamente como é desejável ao cidadão.

Assim, pode-se dizer que educar o cidadão por meio de uma razão contrária aos valores de cidadania seria um contrassenso. No caso específico da democracia e da solidariedade, como seria possível contemplá-las por meio de uma prática eivada de métodos autoritários?

Refutando a atitude baseada no ditado popular "faça o que digo, mas não faça o que faço", Cortina (1993) ressalta que a educação orientada por métodos dialógicos é melhor sucedida, pois estes, carregam no relacionamento entre os participantes do diálogo, os valores de liberdade, solidariedade, respeito mútuo e imparcialidade dirigida aos participantes do diálogo. Valores esses, inerentes ao cidadão. 


\section{Considerações finais}

Cultivar a cidadania na escola pressupõe que os seus agentes incorporem uma postura cidadã; é certo que a adesão a um modelo de educação que afronte os valores de liberdade, igualdade, respeito ativo e solidariedade não seria uma alternativa bem sucedida quanto ao objetivo de formar cidadãos. E, nesse sentido, reitera-se as considerações de Rios (2008) quanto à impossibilidade de ensinar valores em meio à contradição.

Moraes (1986) explica que a palavra ensinar é originária do verbo insignare, que significa "marcar com um sinal, uma letra ou um emblema definitivo". Assim, é impossível não pensar nas consequências das marcas deixadas pela educação, marcas que carregamos por toda a nossa existência.

Seja no âmbito familiar, religioso ou escolar, os sinais deixados podem ser bons ou "gravados a fogo", como diz Moraes (1986). Refletindo acerca da educação escolar, é necessário lembrar que toda ação voltada à usurpação de nossos direitos enquanto homens deixam marcas gravadas à fogo.

Acredito que a marca da cidadania não se faz à fogo, mas com ações que compreendem valores como, respeito, liberdade, solidariedade e igualdade inscritos por uma maneira de ser e agir que eleva o outro a condição equitativa de ser humano.

Assim, acima do compromisso político que a escola possui no tocante à formação de cidadãos, existe o compromisso ético de tratar o outro como um ser igual em dignidade, independentemente de diferenças intelectuais, etárias, sociais, étnicas e assim por diante. Porque antes de sermos cultos, maiores de idade, negros ou amarelos e até mesmo cidadãos, somos igualmente seres humanos.

É certo que, diante da lógica do "sucesso a qualquer preço" vigente nos mais variados âmbitos da sociedade, inclusive na escola, tratar o outro como um ser igual é sinônimo de "nadar contra a maré", mas, para salvar as nossas vidas, muitas vezes conseguimos vencer as correntezas que nos afligem porque nos demos conta dessa necessidade.

Este trabalho dedicou-se a apontar algumas alternativas viáveis aos que desejam nadar contra as correntezas de uma lógica instrumental que ameaça as relações humanas e, mais precisamente a práxis educativa que busca criar condições para o cultivo da cidadania dentro do âmbito escolar.

Partindo-se da ideia de que é impossível ensinar em meio à contradição, demonstrouse a necessidade de superação de valores instrumentais por meio da incorporação de valores 
como a liberdade, a igualdade, o respeito ativo, a solidariedade e o diálogo no trabalho docente.

Refletindo a respeito de liberdade foi possível visualizar a potencialidade de elevar o indivíduo à condição de ser autônomo e reflexivo em relação a si mesmo e ao mundo do qual faz parte. À igualdade foi atribuída uma percepção que eleva os diferentes serem ao status de iguais em dignidade. No tocante ao respeito ativo buscou-se superar a ideia de tolerância e sua consequente exaltação ao individualismo, ressaltando-se assim a possibilidade de compreender e respeitar ideais distintos. Quanto à solidariedade buscou-se superar opiniões que lhe remeteram a um tom assistencialista, tornando a como uma espécie de sustentáculo das relações simétricas entre os indivíduos, nas quais a prevalência dos interesses universais em detrimento dos individuais é garantida. Já, em relação ao diálogo destacou-se a perspectiva de um inevitável comprometimento que envolve os indivíduos num ato racional e capaz de colocar em prática todos os valores aqui mencionados.

Convém ressaltar que este trabalho não teve a pretensão de oferecer uma receita pronta, pois, diante da complexidade humana, entende-se que essa tarefa seria impossível de ser concretizada por um ser igualmente humano. Inclusive, com grande pesar constata-se que, conquanto o docente consiga colocar em prática uma educação dialógica, não há garantias de que isso seja o suficiente para formar o cidadão, mesmo porque é impossível que a escola por si só seja capaz de realizar uma tarefa que requer a participação coletiva. Porém, as tentativas de construir um mundo melhor, de abandonar paradigmas que reiteradamente se demonstram perniciosos à coletividade é um ponto de partida que se compreende como essencial.

Desse modo, tem-se a esperança de que a superação da contradição entre a teoria e a prática seja possível, pois, se formar o cidadão é uma meta, um bom ponto de partida consiste em tratar todos os seres humanos, indistintamente, como cidadãos, dentro e fora das escolas.

\section{EDUCATION IN VALUES: A POSSIBLE WAY TO OVERCOME INSTRUMENTAL REASON TOWARDS CITZEN FORMATION}

ABSTRACT: This paper proposes a reflection on the introduction of values into institutional educational action, the purpose of which is the implementation of a fruitful space for the development of the citizen. Drawing upon the works of the Spanish philosopher Adela Cortina and the German philosopher Jürgen Habermas, it seeks to establish reasoning on the inevitable inclusion of values in such action designed to provoke the students to incorporate a participative attitude, which is essential to raise them to the condition of citizen. It first analyses the different forms of establishment of interpersonal relations. From the considerations of Cortina on the studies of Jonathan Sacks and Thomas Hobbes, a 
comparison is drawn between alliance and contract, demonstrating that although the rights and duties of the citizen are established by means of a contract, their foundations and the guarantee of their functioning represent the alliance. Another point raised refers to surpassing instrumental action, considered by Curtain as detrimental to the formation of the autonomous subject. The contribution of school education in all its levels is highlighted regarding the development of a democratic society that count on the active participation of its pertaining subjects who are aware of its alliances. It points out that for this project to approach reality it is fundamental that educators, as well as the other agents linked to educational institutions, articulate in their praxis the minimum values highlighted by Adela Cortina, namely: freedom, equality, active respect, solidarity and dialog.

KEYWORDS: Citizenship. Education. Values.

\section{REFERENCIAS}

ADORNO, T. W; HORKHEIMER, M. Dialética do esclarecimento: fragmentos filosóficos. Tradução Guido Antônio de Almeida. Rio de Janeiro: Zahar, 1985.

BRANDÃO, C. R. O que é educação? São Paulo: Brasiliense, 1991.

BOFF, L. Saber cuidar: ética do humano e compaixão pela terra. Petrópolis: Vozes, 2004.

BUBER, M. Eu e tu. Tradução Newton Aquiles Von Zuben. 2. ed. São Paulo: Moraes, 1974.

CORTINA, A. Aliança e contrato. São Paulo: Loyola, 2008.

Cidadãos do mundo: para uma teoria da cidadania. São Paulo: Loyola, 2005.

. Ética aplicada e democracia radical. Madrid: Tecnos, 1993.

Ética mínima. São Paulo: Martins Fontes, 2009.

CORTINA, A.; NAVARRO, E. M. Ética. Madrid: Akal, 2001.

FREITAG, B. A teoria crítica ontem e hoje. São Paulo: Brasiliense, 1986.

GOERGEN, P. Educação moral: adestramento ou reflexão comunicativa? Educação e sociedade, São Paulo, v.22, n.76, out., 2001.

HABERMAS, J. Consciência moral e agir comunicativo. Rio de Janeiro: Tempo Brasileiro, 2003a.

O discurso filosófico da modernidade. Lisboa: Publicações Dom Quixote, 1990.

Teoría de la acción comunicativa: complementos y estúdios previos. 4. ed.

Madrid: Cátedra, 2001.

.Teoría de la acción comunicativa: racionalidad de la acción y racionalización social.

4. ed. Madrid: Taurus, 2003 b. 
HERMANN, N. Validade em educação: intuições e problemas na recepção de Habermas. Porto Alegre: EDIPUCRS, 1999.

HOBBES, Thomas. Leviatã ou a matéria, forma e poder de um estado eclesiástico e civil. São Paulo: Ícone, 2008.

MAIA, B. P.; BANDEIRA, J. B. Ação comunicativa na escola: possibilidades da teoria da ação comunicativa de Jürgen Habermas. Cadernos da Escola de Educação e Humanidades, Curitiba, v.1, n.4, p.1-9, [19--].

MORAES, R. O que é ensinar? São Paulo: EPU, 1986.

MÜHL, E. H. Habermas e a educação: ação pedagógica como agir comunicativo. Passo Fundo: UPF, 2003.

OLIVEIRA. M. A. Ética e racionalidade moderna. São Paulo: Loyola, 1993.

PIZZI, J. Ética do discurso: a racionalidade ético-comunicativa. Porto Alegre: EDIPUCRS, 1994.

RIOS, T. A. Aula: gênese, dimensões, princípios e práticas. In: VEIGA, I. P. A. (Org.). Aula: gênese, dimensões, princípios e práticas. Campinas: Papirus, 2008.

SACKS, J. Para curar um mundo fraturado: a ética da responsabilidade. São Paulo: Sêfer, 2005.

WEBER, M. Economia e sociedade: fundamentos da sociologia compreensiva. São Paulo: Ed. da UNB, 2004. 